\title{
The Impact of Perceived Organizational Support and Core Self-Evaluation on Employee’s Psychological Well-Being
}

\author{
Chao Ni, Ying Wang \\ School of Government, Beijing Normal University, Beijing, China \\ Email: nichao2011@126.com, xjtuwy@sina.com
}

Received 8 June 2015; accepted 22 June 2015; published 25 June 2015

Copyright (C) 2015 by authors and Scientific Research Publishing Inc.

This work is licensed under the Creative Commons Attribution International License (CC BY). http://creativecommons.org/licenses/by/4.0/

(c) (7) Open Access

\begin{abstract}
Psychological well-being (PWB) is a concept different from subjective well-being in positive psychology. PWB is conceptualized as a construct which includes the happy emotional experience and the realization of individual potential. This paper assumes that employee's core self-evaluation and their perceived organizational support have a positive effect on psychological well-being. The result based on 441 valid questionnaires supports our hypothesis that employee's core self-evaluation and their perceived organizational support are positively related to their reported psychological well-being. Core self-evaluation is also found to moderate the association of perceived organizational support with PWB in such that POS is more strongly related to PWB for employees who are higher, compared with those lower in CSE.
\end{abstract}

\section{Keywords}

Perceived Organizational Support, Psychology Well-Being, Core Self-Evaluation

\section{Introduction}

While China is focusing on the economic development, its attention is also increasingly shifted to the issue of national happiness, especially the discussion about the question "Are you happy" generated by the CCTV in 2012. This discussion has caused a deep thinking for the happiness of Chinese people. In the view of philosophy, well-being includes two basic types: hedonic and eudemonia. The former regards well-being as a happy experience; the latter thinks well-being is not only a feeling of happiness, but also a perfect experience by fully exerting the potential. Therefore, there are also two different orientations of positive psychology to the well-being of the research: subjective well-being in the view of hedonic and psychology well-being in the view of eudemonia. From the overall perspective of life, well-being is involved in several areas, such as work, family, and in- 
come. In addition, well-being is associated with life satisfaction, positive or negative emotional experience. So they are referred as subjective well-being. Meanwhile, when involved in the area of career development and goal achievement, well-being means personal growth, autonomy, praise, good interpersonal etc. This happiness related to self-fulfillment is called psychological well-being.

The concept of psychology well-being (PWB) was presented by Ryff et al. in 1980s. He deemed that well-being was not only a feeling of happiness, but also a perfect experience by fully exerting the potential. Waterman thought self fulfilling well-fare includes the experience of job involvement, experience with a sense of behavior, a strong sense of activity, a sense of focus on something, and a sense of life and a feeling of being [1]. Ryff thought well-fare contains six dimensions: self-acceptance, purpose in life, personal growth, positive relation with others, environment master, and autonomy [2] [3]. Ryan and Deci claimed that the needs of ability, relationship and autonomy were the basic elements of building psychological well-being [4].

Therefore, psychology well-being is a different feeling from subjective well-fare. It is focused on self-development and growth, instead of just focusing on the emotional experience, so it is stable. Besides, the total evaluation of psychology well-being is different from the subjective well being. The psychological well-being is related with the specific situation, so the interpretation of the well-fare is more accurate and meticulous.

In order to explore the influencing factors of psychology well-being, Diener's study is taken into consideration. In that study he divided the factors with internal factors and external factors (Diener, 1999) [5]. The external factors refer to the variety of objective situations that affect well-fare; internal factors are the personality traits of the individual. Perceived organizational support (POS) is the full sense and views on organizational degree of attention for their contribution and well-fare [6]. It is influenced by organizational fair environment, working conditions, leadership and organization reward etc. [7]. Core self-evaluation is the basic evaluation of individual's ability and value [8], so it is an important role in the work behavior and attitude, which reflects the personality of the individual. According to the viewpoint of the interactive psychology, the situation and the individual feature can be combined to affect the individual's reaction to the established situation (Chatman, 1991) [9]. Lots of environmental characteristics in organization and employees' individual characteristics can be combined, profoundly affecting employee behavior and attitude. Thus, it can be inferred that the organizational support and the core self-evaluation as the individual characteristics of the environmental characteristics can affect the well-being of the employees (Wang \& Sun, 2012) [10].

According to correlative research, although studies have focused on the effects of perceived organizational support on subjective well-being, these studies show that perceived organizational support on job satisfaction and positive emotions has a very good prediction effect [11]. It is not easy for the staff feeling the sense of organization support to fall into failure on the mood [12]. So we think that organizational support is the antecedents of subject well-being. However, little is known about the influence of psychological well-being. As the basic assessment of ability and value, core self-evaluations can not only influence life satisfaction positively [13] [14] (Judge et al., 1998; Judge et al., 2005) but also can adjust the relationship between well-being and physical health [15] (Tsaousis, Nikolaou, Serdaris \& Judge, 2007). For the unemployed, core self-evaluations can also adjust the relationship between employment commitment and well-being [16] (Creed, Lehmann\& Hood, 2009). However, whether organizational support can positively predict psychological well-being and whether core selfevaluation is associated with psychological well-being have not been verified yet. Besides, further verification is required to research how interaction between organizational support and core self-evaluation affects psychological well-being. The purpose of this study is to explore the relationship not only between organizational support and psychological well-being but also between core self-evaluations and psychological well-being. Furthermore, we will focus on the core self-evaluation in adjustment between the two variables. On one hand, we will theoretically validate whether we can enhance employees’ psychological well-being by providing organizational support. Moreover, we hope to know more about psychological well-being of different employees with different temperament types. On the other hand, we will provide practical implications for the enterprise to promote employees' physical and mental health and improve their work performance so that the enterprise can achieve good employment relationship.

\section{Theoretical Assumptions}

\subsection{The Relationship between Perceived Organizational Support and Psychological Well-Being}

Based on the definitions of psychological well-being of scholars summarized, the study found the psychological 
well-being is just the emotional happiness experience. It is more focused on the realization of the individual potentials and the realization and manifestation of human essence. Ryff deems that the three most important factors in the six dimensions of psychological well-being [17] includes the ability to pursue the goal of life, the harmonious interpersonal-relationship and the mastery of the respect for oneself. Ryan \& Deci also considers that the ability need, the autonomy need and relationship need are the basic elements of psychological well-being. So the study regards the three basic dimensions of psychological well-being as competency, good relationship and autonomy.

Academic community generally uses perceived organizational support to measure organizational support [7]. On one hand, the organization provides opportunities for employees of learning and development to help employees grow. At the same time it can provide more recognition, respect and a sense of belonging and more psychological resources to help employees in difficulties, maintain hope and solve the crisis [18] (Tepper, 2001). It can provide direct support for the realization of employee potential. On the other hand, based on Social Exchange Theory, the employees can get the responsibility of the organization after getting support from organization, including high organizational identification, organizational commitment and job satisfaction. The employees can be motivated to study and improve themselves by these positive attitudes and behaviors. From the feedback of the interpersonal support, the employees will care for others and create a good relationship atmosphere more frequently. Besides, the responsibility to achieve organization's goals and interests will offer higher working autonomy for employees [19] (Eisenberger et al., 1986). This leads to the following hypothesis:

H1: Perceived organizational support is positively related to psychological well-being.

\subsection{The Relationship between Core Self-Evaluation and Psychological Well-Being}

The core self-evaluation is the integration of the 4 qualities of stability, self-esteem, self-efficacy and control points, a potential deep description of the personality and the basic evaluation for individual's ability and value [8]. It has an extra explanatory power to predict individual behavior and attitude compared to the big five personality framework [20]. It has been proved that the employees who own high self-esteem have a higher professional prestige and incomes in the development of the occupation [21]. So it's inferred that they are more likely to have good working performance and interpersonal and employees who owns high self-esteem and high selfefficacy have higher satisfaction to work and life [14]. Besides, the employees who have high core self-evaluation tend to react positively to the environment and perceive adverse information in a lower degree to maintain their positive cognition and emotions. They believe that the job they take is more challenging and more meaningful, so they give the job a higher evaluation, and then complete the work better [22] [23] (Kacmar et al., 2009; Judge \& Hurst, 2007). Therefore, It can be considered that the employees who own high core self-evaluation are driven by internal motivation. They will play a subjective initiative in promoting the realization of self potential and take positive actions to achieve higher goals. And their features including optimistic and passionate, will also promote the realization of challenging tasks and bring positive views on themselves and the environment, so they will have a higher psychological well-being. This leads to the following hypothesis:

H2: The core self-evaluation is positively related to the psychological well-being.

\subsection{The Regulating Effect of Core Self-Evaluation}

Based on Resource Preservation Theory [24] [25] (Hobfoll, 1989, 2002), the individuals have the instinct to acquire and maintain their resources, such as time, physical, emotional and attention and so on. When the individuals are in the environment where he feels to lose some resources possibly, they will have the feeling of stress and insecurity, then they will gain some resources to make up for the loss by all means [26]. Studies have shown that individuals with high core self evaluations tend to experience less stress and tension and use avoidant coping strategies in a lower degree [27] (Kammeyer, 2009). When they feel the change of organization support, the high core self-evaluation people have more psychological resources and take a positive view of themselves and the environment. Therefore, the impact of organizational support on the psychological well-fare is not strong. Besides, based on Behavior Elasticity Theory [28] (Brockner, 1988), the individual's response to the external situation is influenced by the individual characteristics. For high self-efficacy and internal control type of employees, the influence of the situation is relatively weak. The employees who have high level core self-evaluation own a strong sense of self-esteem and self-efficacy and they can control the environment. So their cognition, emotion, attitude and behavior are more controlled by themselves instead of external organizational support. 
This leads to the following hypothesis:

H3: The core self-evaluation plays a regulating role in the relationship between perceived organizational support and psychological well-being. And the impact of perceived organizational support on the psychological well-being is stronger for low core self-evaluation employees.

\section{Method}

\subsection{Sample}

The sample for the study was drawn from employees working in all types of companies in Beijing, Shandong, Hebei, Fujian and Sichuan. Out of the total 500 questionnaires distributed, 441 copies were returned and all of them were valid. The effective rate of recovery is $88.2 \%$. The statistical characteristics of demographic variables were shown in Table 1.

\subsection{Measures}

1) Organizational support. Scale developed by Eisenberger, Huntington, Hutchison, and Sowa (1986) were used in this study. The original scale contained 36 items, after a series of selection, the official scale represent organizational support contained six items with high load capacity selected by relevant scholars and used 5-point rating technique, the higher the score, the higher the organizational support. Reliability and validity of the scale have been obtained validation support by some studies (Shore and Wayne, 1993). And the Cronbach's $\alpha$ coefficient of this scale was 0.935 .

2) Psychological well-being. Right now the psychological well-being scale developed by Ryff receive most attention in relevant studies, but when this scale used in China's urban population groups, it did not get good results, especially the construct validity was poor [29]. So in this paper, we consider revising current scale. The competency measurement in psychological well-being scale was based on three topics of work well-being scale developed by Warr [30] (1990); the dimension of good relations were referenced to the human relationships Part of Ryff's (1989) psychological well-being scale and include 4 items; autonomy measurement was based on five topics of work well-being scale developed by Wen Feng [31] (2006). Comprising a total of 12 subject of a questionnaire, after analysis of reliability and validity, the final form of the questionnaire include nine items. The measures were based on a five-point scale from 1 ("never") to 5 ("frequently") and the Cronbach's $\alpha$ coefficient of this scale was 0.855 .

3) Core self-evaluation. The core self-evaluation scale developed by Judge, Bono and Thoresen (2003) were used in this study [20]. This scale includes 12 items and can directly measure the core self-evaluations, which reflect four dimensions of general self-efficacy, neuroticism, self-esteem and control point, and directly access to the core of self-evaluation scores. The Cronbach's $\alpha$ coefficient of this scale was 0.902 .

\subsection{Common Method Biases Test}

Considering the data in this paper were reported by employees at the same time, there may be a common method bias problem, so we use the Harman single factor test to verify the extent of common method biases of each research variable. 26 items of 3 questionnaires were analyzed, and 3 factors were determined. The results show that there are three factors' characteristic root more than $1,58.25 \%$ of the total variance explained, where the first factor explains $39.88 \%$ variation, non-rotated factor structure does not appear in a common factor. The results demonstrated that common method bias is not an issue in this study.

\subsection{Data Processing}

This study used SPSS 20.0 to implement descriptive statistics, correlation analysis, reliability analysis and

Table 1. Statistical characteristics of demographic variables.

\begin{tabular}{cccc}
\hline Gender & Age & Education background & Work experience \\
& Under 25: 182 & Less than college: 54 & \\
Male: 149 & C6 - 35: 228 & College: 191 & 5 years and under: 333 \\
Female: 292 & Above $36: 31$ & Bachelor: 133 & S years and above: 108 \\
& & Master and above: 63 & \\
\hline
\end{tabular}


regression analysis.

\section{Results}

\subsection{Descriptive Statistics and Correlation Analysis of Variables}

Table 2 shows the results of descriptive statistics and correlation analysis of variables. As we can see, organizational support $(\mathrm{r}=0.51, \mathrm{p}<0.01)$ and core self-evaluations $(\mathrm{r}=0.76, \mathrm{p}<0.01)$ both have a significantly positive correlation with psychological well-being, which is consistent with the hypothesis.

\subsection{Organizational Support and PWB, Core Self-Evaluation and PWB's Relationship}

In Table 3, after controlling gender, age and other demographic variables (Model 1), we introduce the

Table 2. Means, standard deviation, Pearson correlation coefficient of variables.

\begin{tabular}{|c|c|c|c|c|c|c|c|c|c|c|}
\hline & Means & SD & 1 & 2 & 3 & 4 & 5 & 6 & 7 & 8 \\
\hline 1) Gender & 1.68 & 0.47 & 1.00 & & & & & & & \\
\hline 2) Age & 1.58 & 0.49 & $-0.12^{*}$ & 1.00 & & & & & & \\
\hline 3) Education background & 2.50 & 0.86 & $-0.12^{*}$ & $0.44^{* *}$ & 1.00 & & & & & \\
\hline 4) Work experience & 1.96 & 0.87 & -0.03 & $0.48^{* *}$ & 0.08 & 1.00 & & & & \\
\hline 5) Position & 1.33 & 0.54 & $-0.17^{* *}$ & $0.17^{* *}$ & 0.00 & $0.20^{* *}$ & 1.00 & & & \\
\hline 6) Organizational support & 3.18 & 0.89 & 0.00 & 0.06 & $0.22^{* *}$ & 0.05 & $0.19^{* *}$ & 1.00 & & \\
\hline 7) $\mathrm{PWB}$ & 3.70 & 0.58 & 0.02 & $0.14^{* *}$ & $0.18^{* *}$ & 0.09 & $0.13^{* *}$ & $0.51^{* *}$ & 1.00 & \\
\hline 8) Core self-evaluation & 3.67 & 0.59 & -0.01 & $0.13^{* *}$ & $0.18^{* *}$ & 0.09 & $0.14^{* *}$ & $0.47^{* *}$ & $0.76^{* *}$ & 1.00 \\
\hline
\end{tabular}
${ }^{*} \mathrm{p}<0.05,{ }^{* *} \mathrm{p}<0.01$ (2-tailed).

Table 3. Core self-evaluation's moderating effect on organizational support and PWB.

\begin{tabular}{|c|c|c|c|}
\hline & \multicolumn{3}{|c|}{ Dependent variable: PWB } \\
\hline & Model 1 & Model 2 & Model 3 \\
\hline \multicolumn{4}{|l|}{ Control variable } \\
\hline Gender & 0.06 & 0.04 & 0.04 \\
\hline Age & 0.03 & 0.06 & 0.06 \\
\hline Education background & $0.17^{* *}$ & -0.01 & 0.00 \\
\hline Work Experience & 0.04 & 0.02 & 0.01 \\
\hline Position & $0.13^{* *}$ & 0.00 & 0.00 \\
\hline \multicolumn{4}{|l|}{ Independent variable } \\
\hline Organizational support & & $0.21^{* *}$ & $0.23^{* *}$ \\
\hline Core self-evaluation & & $0.66^{* *}$ & $0.64^{* *}$ \\
\hline \multicolumn{4}{|l|}{ Interaction term } \\
\hline Organizational support $\times$ core self-evaluation & & & $-0.09^{* *}$ \\
\hline $\mathrm{R}^{2}$ & 0.057 & 0.624 & 0.631 \\
\hline Adjusted $\mathrm{R}^{2}$ & 0.045 & 0.6217 & 0.624 \\
\hline$\Delta \mathrm{R}^{2}$ & 0.057 & 0.344 & 0.007 \\
\hline $\mathrm{F}$ & $4.773^{* *}$ & $93.805^{* *}$ & $84.426^{* *}$ \\
\hline
\end{tabular}

${ }^{*} \mathrm{p}<0.05,{ }^{* *} \mathrm{p}<0.01$ (2-tailed). 
independent variable of organizational support and moderating variable of core self-evaluations (Model 2). It showed that after introducing the independent variable of organizational support and moderating variable of core self-evaluations, organizational support and core self-evaluations together explained 34.4\% of total variance of psychological well-being, which was very significant. Organizational support $(\beta=0.21, \mathrm{p}<0.001)$ and core self-evaluations $(\beta=0.66, \mathrm{p}<0.001)$ showed a significant positive correlation with psychological well-being, Hypotheses 1 and 2 were tested.

\subsection{Core Self-Evaluation's Moderating Effect on Organizational Support and PWB}

In order to verify the moderating effect of core self-evaluations, select hierarchical regression analysis (Table 3) were used: first introduce gender age and other demographic variables as control variables into the model 1 , then add the independent variable of organizational support and moderating variable of core self-evaluations (Model 2 ), and finally introduce interaction term standardized organizational support $\times$ standardized core self-evaluation (model 3).

In model 3 , the interaction effect of organizational support and core self-evaluations can explain $0.7 \%$ of the total variance, the moderating effect is significant $(\beta=-0.09, \mathrm{p}<0.05)$. This indicates that core self-evaluation is the moderating variable of the relationship between organizational support and psychological well-being. Further regression analysis showed a significant positive correlation $(\beta=0.13, \mathrm{p}<0.05)$ between organizational support and psychological well-being, but to the employees with low core self-evaluations, the positive correlation between organizational support and psychological well-being is even higher $(\beta=0.42, \mathrm{p}<0.001)$. Figure 1 shows the relevant trends of organizational support and core self-evaluations in groups of employees with high core self-evaluation and groups of employees with low core self-evaluation. It also verified the hypothesis 3 of this article, which is core self-evaluation has a moderating effect on organizational support and PWB. It should be noted that the moderating effect in this study is relevant small, but in the organization management area, interaction item explains one percent of the total variance is not uncommon. From the methodological point of view, there may be two reasons for the weakness of moderating effect. First, Jaccard and Wan (1995) pointed out that the measurement error of variables can affect moderating effect [32]. In this study, all the variables were come from measurement, so there was an inevitable error of measurement, and therefore weaken the moderating effect. Secondly, Siemsen, Roth and Oliveira [33] (2010) pointed out that a common method bias will reduce the moderating effect. Although this article does not have serious problems of common method bias, but all of the variables in this study were self-reported by employees, so it can not completely avoid the common method bias problem, which may to some extent inhibited the moderating effect.

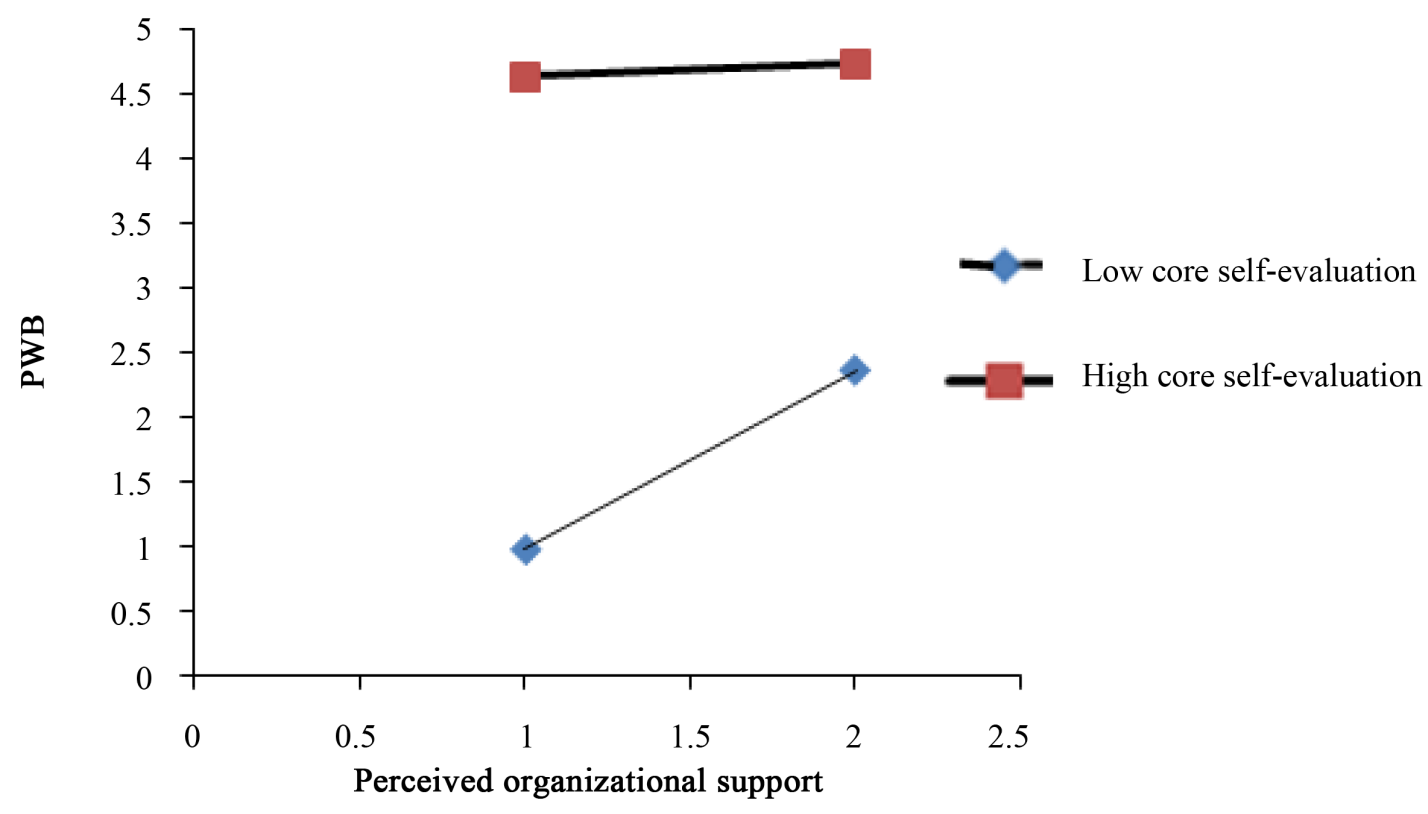

Figure 1. Core self-evaluation's moderating effect on perceived organizational support and PWB. 


\section{Discussion}

The analysis of the data shows that organizational support can positively predicted psychological well-being, hypothesis 1 is tested. Organizational support has two core elements: first, employees' perception of whether the organization value their contribution; second, employees' perception of whether the organization concerns their psychological well-being. Employees usually take the individual effort as the degree of contribution to the organization, and whether their social emotional need is satisfied as the measure of how the organization value their psychological well-being. Based on social exchange theory, the behavior of employees originates from the exchange activities which can bring them benefits and rewards, employees with high organizational support have a higher expectation to get reward and concern, and therefore will put more effort and reward the organization with better performance and positive social-emotional state, then the individual's self-worth is more likely to achieve and maintain, and then get a higher degree of psychological well-being.

The verification of hypothesis 2 is consistent with the results of Judge's study, Judge considered positive core self-evaluations would improve individual's job satisfaction, and has a good job performance. Other studies also believes that core self-evaluations will actively affect job search behavior [34] (Wanberg, Glomb, Song \& Sorenson, 2005), goal setting [35] (Erez \& Judge, 2001), career success [36] (Judge \& Hurst, 2008), work relationships [37] (Seott \& Judge, 2009) and organizational commitment [38] (Ng \& Feldman, 2010), etc. Therefore, on the one hand core self-evaluation as an evaluation factor directly affects happiness, and make employees with high core self-evaluation evaluate the environment and themselves higher; on the other hand, the core selfevaluations can also be used as an indirect factor, play a role in the behavior of employees, and enhance the psychological well-being of employees through better work performance, higher goals and good relationship and other factors.

In addition, when comparing the impact of organizational support on psychological well-being and the impact of core self-evaluation on psychological well-being, it is not difficult to find that the impact of core self-evaluation on psychological well-being is stronger than organizational support's impact. This shows that compared with the external situation, the individual's own personality would better determine their feelings of happiness, which is consistent with previous findings. Many studies show that happiness has stability, that's because external factors often activated by a subjective process, personality traits affect life events, and further affect the well-being, and personality has its inherent internal structure, so this kind of impact is extended and stable. Judge [13] (1998) proposed that core self-evaluation has been verified as self-evaluated, deep and wild-ranged of personality structure of personality, it has strong stability and are important indicators of personality variables, so core self-evaluation can better explain the variables of psychological well-being.

The verification of hypothesis 3 indicates that core self-evaluations plays a moderating role in the relationship between organizational support and psychological well-being, the impact of organizational supports on psychological well-being with low core self-evaluation is stronger than the impact of organizational supports on psychological well-being with high core self-evaluation sensation, which well confirms the behavior elastic theory. Employees with high core self-evaluation tend to have a higher level of self-esteem and self-efficacy, these employees have better control over the environment and changes in the external situation has a weak influence on their cognition, mood, behavior and attitudes. For those employees who have high core self-evaluation, because they have more confident about the environment and their own ability, regardless of the feedback from the outside world is positive or negative, they can stick to the goal and keep being motivated and constructive [39] (Bono \& Colbert, 2005), so when faced with the task, no matter how the external environment is, they are more likely to get high achievement and satisfaction, so that the self-realization of happiness of theirs are met. Meanwhile, because employees with high core self-evaluation have a low dependence on environment support, the level of organizational support hardly influence their sense of happiness, therefore the psychological well-being of these employees are also more stable.

\section{Conclusion}

This study has the following inspirations on organizational management practices: First, organizations should recognize the well-being of employees comprehensively from different angles; the human care of the organization to its own employees should not only be limited in providing a happy emotional experience, but also be concern about the potential development and self-realization of the employees. Second, organizations should provide employees with a variety of material and spiritual support such as fairness, reward and work environ- 
ment, help employees improve themselves, and realize the value of their life. Third, when preparing recruitment and selection, succession planning, promotion and other activities involved in human resource management, organizations should be consciously the concerned the process of employees' self-evaluation.

The deficiencies of this study are: At first, this study did not conduct a across time longitudinal study; crosssectional study is difficult to accurately investigate the causal relationships between variables. Second, the data of this study were reported by the employees, so the common methods bias could have an impact on the results.

Main directions of future research are: First, continue to focus on other factors that affect employees’ psychological well-being, as well as the interaction effect of various factors, deepen the understanding of psychological well-being, so as to better serve business management practices. Second, further expand the sample of the study, not only concern about the psychological well-being of employees in an enterprise environment, but also carry out research for the different population groups in society and provide theoretical and practical guidance for better implementation of gross national happiness.

\section{References}

[1] Waterman, A.S. (1993) Two Conceptions of Happiness: Contrasts of Personal Expressiveness (Eudaimonia) and Hedonic Enjoyment. Journal of Personality and Social Psychology, 64, 678-691. http://dx.doi.org/10.1037/0022-3514.64.4.678

[2] Ryff, C.D. (1989) Happiness Is Everything, or Is It? Explorations on the Meaning of Psychological Well-Being. Journal of Personality and Social Psychology, 57, 1069-1081. http://dx.doi.org/10.1037/0022-3514.57.6.1069

[3] Ryff, C.D. and Keyes, C.L.M. (1989) The Structure of Psychological Well-Being Revisited. Journal of Personality and Social Psychology, 69, 719-727. http://dx.doi.org/10.1037/0022-3514.69.4.719

[4] Ryan, R.M. and Deci, E.L. (2000) Self-Determination Theory and the Facilitation of Intrinsic Motivation, Social Development, and Well-Being. American Psychologist, 55, 68-78. http://dx.doi.org/10.1037/0003-066X.55.1.68

[5] Diener, E., Eunkook, S., Richard, L., et al. (1999) Subjective Well-Being: Three Decades of Progress. Psychological Bulletin, 125, 276-302. http://dx.doi.org/10.1037/0033-2909.125.2.276

[6] Robert, E. (1986) Robin Huntington: Perceived Organizational Support. Journal of Applied Psychology, 71, 500-507. http://dx.doi.org/10.1037/0021-9010.71.3.500

[7] Rhoades, L. and Eisenberger, R. (2002) Perceived Organizational Support: A Review of the Literature. Journal of Applied Psychology, 87, 698-714. http://dx.doi.org/10.1037/0021-9010.87.4.698

[8] Judge, T.A., Locke, E.A. and Durham, C.C. (1997) The Dispositional Causes of Job Satisfaction: A Core Evaluations Approach. Research in Organizational Behavior, 9, 151-188.

[9] Chatman, J.A. (1991) Matching People and Organization: Selection and Socialization in Public Accounting Firms. Administrative Science Quarterly, 36, 459-484. http://dx.doi.org/10.2307/2393204

[10] Wang, Z. and Sun, J. (2012) The Influence of Core Self-Evaluation, and Organizational Support on Subjective/Objective Career Success: An Internationalist Perspective. Chinese Journal of Management, 9, 1307-1313.

[11] Olson, M.L., Hugelshofer, D.S., Kwon, P. and Reff, R.C. (2005) Rumination and Dysphoria: The Buffering Role of Adaptive Forms of Humor. Personality and Individual Differences, 39, 1419-1428. http://dx.doi.org/10.1016/j.paid.2005.05.006

[12] Martin, R.A. and Lefcourt, H.M. (1983) Sense of Humor as a Moderator of the Relation between Stressors and Moods. Journal of Personality and Social Psychology, 45, 1313-1324. http://dx.doi.org/10.1037/0022-3514.45.6.1313

[13] Judge, T.A., Erez, A. and Bono, J.E. (1998) The Power of Being Positive: The Relation between Positive Self-Concept and Job Performance. Human Performance, 11, 167-187. http://dx.doi.org/10.1080/08959285.1998.9668030

[14] Judge, T.A., Bono, J.E., Erez, A. and Locke, E.A. (2005) Core Self-Evaluations and Job and Life Satisfaction: The Role of Self-Concordance and Goal Attainment. Journal of Applied Psychology, 90, 257-268. http://dx.doi.org/10.1037/0021-9010.90.2.257

[15] Tsaousis, I., Nikolaou, I., Serdaris, N. and Judge, T.A. (2007) Do the Core Self-Evaluations Moderate the Relations between Subject Well-Being and Physical and Psychological Health? Personality and Individual Differences, 42, 1441-1452. http://dx.doi.org/10.1016/j.paid.2006.10.025

[16] Creed, P.A., Lehmann, K. and Hood, M. (2009) The Relationship between Core Self-Evaluations, Employment Commitment and Well-Being in the Unemployed. Personality and Individual Differences, 47, 310-315. http://dx.doi.org/10.1016/j.paid.2009.03.021

[17] Ryff, C.D. and Singer, B. (1998) The Contours of Positive Human Health. Psychological Inquiry, 9, 1-28. http://dx.doi.org/10.1207/s15327965pli0901_1 
[18] Tepper, B.J. (2001) Health Consequences of Organizational Injustice: Tests of Main and Interactive Effects. Organizational Behavior and Human Decision Processes, 86, 197-215. http://dx.doi.org/10.1006/obhd.2001.2951

[19] Eisenberger, R., Huntington, R., Hutchison, S. and Sowa, D. (1986) Perceived Organizational Support. Journal of Applied Psychology, 71, 500-507. http://dx.doi.org/10.1037/0021-9010.71.3.500

[20] Judge, T.A., Bono, J.E. and Thoresen, C.J. (2003) The Core Self-Evaluations Scale: Development of a Measure. Personnel Psychology, 56, 301-331. http://dx.doi.org/10.1111/j.1744-6570.2003.tb00152.x

[21] Kammeyer-Mueller, J.D., Judge, T.A. and Piccolo, R.F. (2008) Self-Esteem and Extrinsic Career Success: Test of a Dynamic Model. Journal of Applied Psychology, 57, 204-224. http://dx.doi.org/10.1111/j.1464-0597.2007.00300.x

[22] Kacmar, K.M., Collins, B.J., Harris, K.J. and Judge, T.A. (2009) Core Self-Evaluations and Job Performance: The Role of the Perceived Work Environment. Journal of Applied Psychology, 94, 1572-1580. http://dx.doi.org/10.1037/a0017498

[23] Judge, T.A. and Hurst, C. (2007) Capitalizing on One’s Advantages: Role of Core Self-Evaluations. Journal of Applied Psychology, 92, 1212-1227. http://dx.doi.org/10.1037/0021-9010.92.5.1212

[24] Hobfoll, S.E. (1989) Conservation of Resources: A New Attempt at Conceptualizing Stress. American Psychologist, 44, 513-524. http://dx.doi.org/10.1037/0003-066X.44.3.513

[25] Hobfoll, S.E. (2002) Social and Psychological Resources and Adaptation. Review of General Psychology, 6, $307-324$. http://dx.doi.org/10.1037/1089-2680.6.4.307

[26] Hobfoll, S.E. and Shirom, A. (2000) Conservation of Resources Theory: Applications to Stress and Management in the Workplace. In: Golembiewski, R.T., Ed., Handbook of Organization Behavior, Marcel Dekker, New York, 57-80.

[27] Kammeyer-Mueller, J.D., Judge, T.A. and Scott, B.A. (2009) The Role of Core Self-Evaluations in the Coping Process. Journal of Applied Psychology, 94, 177-195. http://dx.doi.org/10.1037/a0013214

[28] Brockner, J. (1988) Self-Esteem at Work: Research, Theory and Practice. D.C. Heath \& Co, Lexington.

[29] Xing, Z. and Huang, L. (2004) Study of Applying to Citizens in China on Ryff's Psychological Well-Being Scales. Health Psychology Journal, 12, 231-233.

[30] Peter, W. (1990) The Measurement of Well-Being and Other Aspects of Mental Health. Journal of Occupational Psychology, 63, 193-210. http://dx.doi.org/10.1111/j.2044-8325.1990.tb00521.x

[31] Wen, F. (2006) The Study on the Structure of Job-Related Well-Being and Relation. Master’s Thesis, Jinan University, Ji'nan.

[32] Jaccard, J. and Wan, C.K. (1995) Measurement Error in the Analysis of Interaction Effects between Continuous Predictors Using Multiple Regression: Multiple Indicator and Structural Equation Approaches. Psychological Bulletin, 117, 348-357. http://dx.doi.org/10.1037/0033-2909.117.2.348

[33] Siemsen, E., Roth, A. and Oliveira, P. (2010) Common Method Bias in Regression Models with Linear, Quadratic, and Interaction Effects. Organizational Research Methods, 13, 456-476. http://dx.doi.org/10.1177/1094428109351241

[34] Wanberg, C.R., Glomb, T.M., Song Z.L. and Sorenson, S. (2005) Job-Search Persistence during Unemployment: A 10-Wave Longitudinal Study. Journal of Applied Psychology, 90, 411-430. http://dx.doi.org/10.1037/0021-9010.90.3.411

[35] Erez, A. and Judge, T.A. (2001) Relationship of Core Self-Evaluations to Goal Setting, Motivation, and Performance. Journal of Applied Psychology, 86, 1270-1279. http://dx.doi.org/10.1037/0021-9010.86.6.1270

[36] Judge, T.A. and Hurst, C. (2008) How the Rich (and Happy) Get Richer (and Happier): Relationship of Core SelfEvaluations to Trajectories in Attaining Work Success. Journal of Applied Psychology, 93, 849-863. http://dx.doi.org/10.1037/0021-9010.93.4.849

[37] Scott, B.A. and Judge, T.A. (2009) The Popularity Contest at Work: Who Wins, Why, and What Do They Receive? Journal of Applied Psychology, 94, 20-33. http://dx.doi.org/10.1037/a0012951

[38] Ng, T.W.H. and Feldman, D.C. (2010) Idiosyncratic Deals and Organizational Commitment. Journal of Vocational Behavior, 76, 419-427. http://dx.doi.org/10.1016/j.jvb.2009.10.006

[39] Bono, J.E. and Colbert, A.E. (2005) Understanding Responses to Multi-Source Feedback: The Role of Core SelfEvaluations. Personnel Psychology, 58, 171-203. http://dx.doi.org/10.1111/j.1744-6570.2005.00633.x 